Res Publica. Revista de Historia de las Ideas Políticas ISSN-e: 1989-6115

\title{
El Estado total en Carl Schmitt: desbordamiento de lo político y decisión totalitaria: una reconstrucción teórico-doctrinal ${ }^{*}$
}

\author{
Clara Ramas San Miguel**
}

Recibido: 05 de septiembre de 2018 / Aceptado: 14 de diciembre de 2018

Resumen. En Schmitt, "Estado total" mienta dos realidades. Primero, Estado total "por debilidad", o disolución y desbordamiento de lo político por el conflicto social y la lucha de clases en la crisis constitucional alemana. En segundo lugar, Estado total "en el sentido de la cualidad y la energía", cuyo modelo es el Estado nazi de 1933. Para Schmitt sería la respuesta a dicha crisis: un Estado capaz de decidir, como instancia soberana, por encima de los conflictos que desgarran la unidad política, e instaurar la unidad y el combate al enemigo. Ello lo lograría apropiándose de los medios técnicos y sustituyendo la estructura del Estado clásico por una triple (Estado, Movimiento, Pueblo).

Palabras clave: Estado total; técnica; guerra; pueblo; amigo-enemigo.

\section{[en] The Total State in Carl Schmitt: Overflow of the Political and Totalitarian Decision. A Theoretical-Doctrinal Reconstruction}

\begin{abstract}
Total State" designates for Schmitt two phenomena. First, total State "out of weakness": the disolution of the political by social conflict and class struggles during the German constitutional crisis. Second, total State "with regard to quality and energy", whose model is the Nazi State in 1933. According to Schmitt, the later would be the answer to the crisis: a State capable of deciding, as souvereign entity, over the conflicts which tear the political unity, and of reinstalling unity and combat of the enemy. Both would be accomplished by appropiating the technical means and replacing the classic State with a triple structure (State, Movement, Volk).
\end{abstract}

Keywords: Total State; Technicity; War; Volk; Friend-Enemy.

Sumario. Introducción. 1. La necesidad del Estado total: el diagnóstico epocal de Schmitt. 1.1. El problema de la técnica. 1.2. Crisis de Weimar y el "Estado total por debilidad, o cuantitativamente total". 2. La apuesta: el "Estado total en el sentido de la cualidad y la energía". 2.1. La apropiación de los medios técnicos. 2.2. La estructura: Estado, Movimiento, Pueblo. 2.3. La finalidad: Unidad y distinción amigo-enemigo. 3. Conclusiones.

* Este trabajo ha sido realizado en el marco de los siguientes Proyectos de Investigación: Naturaleza y comunidad IV: El filósofo, la ciudad y el conflicto de las facultades, o la filosofía en la crisis de la humanidad europea del Siglo XXI (Ref. FFI2017-83155-P), financiado por Ministerio de Economía, Industria y Competitividad; POSTORY: Historiadores, Mnemohistoria y artesanos del pasado en la era posturística (AGREEMENT NUMBER: 2013 - 1572 / 001 - 001 CU7 MULT7), financiado por CE. EACEA. Culture. Multianual Cooperation Projects. 2007-2013; y Precariedad, exclusión y diversidad funcional (discapacidad): lógicas y efectos subjetivos del sufrimiento social contemporáneo. Innovación docente en Filosofía (Ref.: Innova-Docencia, Proyecto № 148), financiado por la Universidad Complutense de Madrid.

** Universidad Católica de Valencia clara.ramas@pdi.ucm.es 
Cómo citar: Ramas San Miguel, C. (2019). El Estado total en Carl Schmitt: desbordamiento de lo político y decisión totalitaria: una reconstrucción teórico-doctrinal, en Res Publica 22.1, 141-156

\section{Introducción}

El tratamiento de Schmitt del problema del Estado total condensa sin duda la mayor problematicidad en la trayectoria de este pensador que ha sido calificado de "espíritu peligroso" o "enemigo". Este tema aúna dimensiones tanto político-personales o coyunturales como teóricas ${ }^{2}$. Como ha demostrado Kervégan, si nos atenemos a la trayectoria de Schmitt, hubo un afán claro de convertirse en el "jurista de la corte" y una implicación en el régimen ${ }^{3}$. Sin embargo, lo que hubo de oportunismo político, creencia personal o propaganda ideológica, no es el objeto de este artículo: más bien, se tratará aquí de reconstruir la argumentación teórica que permite a Schmitt, en un momento dado, problematizar la cuestión del Estado a partir de la categoría del Estado total.

Que el nivel en el que pretende hablar Schmitt en general es teórico, y más precisamente filosófico, se ve con claridad en textos de corte metodológico, como el Prólogo del 63 a El concepto de lo político, donde explicita sus concepciones de lo político y del Estado de un modo que puede ser la base de otros textos de diagnóstico de la actualidad concreta. Aquí se afirma: "Se trata, en otras palabras, de establecer un marco para determinadas cuestiones de la ciencia jurídica con el fin de poder orden en una temática confusa y hallar así una tópica de sus conceptos"4; esto es, demarcar un campo conceptual. Trabajo, pues, previo a la especialización de la ciencia jurídica, digamos, ya circunscrita a un dominio óntico específico: trabajo

1 Así, G. Balakrishnan, The Enemy: An Intellectual Portrait of Carl Schmitt, London, Verso, 2000, o J.W. Müller, A Dangerous Mind: Carl Schmitt in Post-War European Thought, New Haven and London, Yale University Press, 2003.

2 Ambas dimensiones se mezclan siempre en su trayectoria. Schmitt, como bien ha hecho notar Agamben: precisamente a la vez que siempre se reclamó "jurista" defendió también su implicación en la "constitución material" de su tiempo, y por ello, inmediatamente, en lo político. Afirmaba Schmitt en una entrevista de 1933: "El significado verdadero de mi trabajo deriva de hecho de que no soy otra cosa que el vehículo de la ley sustancial del pueblo del cual soy parte" (citado en G. Agamben, "A jurist confronting himself: Carl Schmitt's jurisprudential thought", en J. Meierhenrich y O. Simons (eds.), The Oxford Handbook of Carl Schmitt, New York, Oxford University Press, 2016, pp. 457-470, aquí p. 458.

3 J.-F- Kervégan, ¿Qué hacemos con Carl Schmitt? Madrid, Escolar y Mayo, 2013, pp. 9-37. Esto es así por mucho que Schmitt lo intentara negar. En su defensa ante el fiscal estadounidense Kempner en el interrogatorio en Nürnberg en 1947 -donde le acusaba de que su teoría del "espacio vital" era una "exposición ideológica de los principios ideológicos para una guerra de agresión", un "ordenamiento jurídico internacional en el sentido de las ideas hitlerianas", y que como tal suponía la colaboración en crímenes de guerra y contra la humanidad-, Schmitt replicó que, si bien reconocía haber sido un "aventurero intelectual" y asumido riesgos, ciertamente no había contribuido a preparar las guerras de agresión (C. Schmitt, Respuestas en Núremberg, Madrid, Escolar y Mayo, 2016, pp. 69-70), y que su teoría sobre el gran espacio [Großraum] se trataba de una investigación de carácter científico, tanto en los motivos como en los contenidos (ibidem, p. 65); defiende "la profunda incompatibilidad entre el «espacio vital» biológico-racial y el «gran espacio» construido racionalmente" (ibidem, p. 89); y alega haber sido presa del "estilo general de un sistema totalitario que erradica aquello que no puede usar y trata de utilizar aquello que no puede erradicar" (ibidem, p. 91). Un estudio clásico sobre la implicación de Schmitt en el Tercer Reich es J. W. Bendersky, Carl Schmitt. Theorist for the Reich, Princeton, Princeton University Press, 1983. Otro reciente: E. S. Passos, "Carl Schmitt's Political Theory during the Third Reich", en The Political Science Review 42-1, 2018, pp. 197-217.

4 C. Schmitt, El concepto de lo político, Madrid, Alianza Editorial, 2009, p. 39. 
sobre los conceptos mismos que articularán ese ámbito de sentido. Y, añade, trabajo de "encuadrar teóricamente un problema inabarcable", esto es, no aceptar las formas dadas de conceptualización, las evidencias, los hábitos de pensamiento. Schmitt se lamenta de que su intento de demarcar un campo conceptual se haya convertido en un "slogan primitivo", una "teoría de...", endosada de oídas al enemigo: en suma, en un cliché. Schmitt se pregunta: ¿cómo pensar ahora sobre lo político? "El tiempo de los sistemas ha pasado" (¿la metafísica dogmática?), y no ha lugar tampoco al aforismo (¿la post-metafísica?): "En el dilema entre sistema y aforismo sólo conozco una salida: mantener presente el fenómeno y someter las cuestiones que brotan incesantemente de situaciones siempre nuevas y tumultuosas a la verificación de sus criterios" . Él, dice, quiere proporcionar "[...] una panorámica sobre las relaciones internas de un campo conceptual. Su objeto es acotar un terreno en el que los conceptos se informan unos a otros en virtud de su posición dentro de aquél"'. Y todo ello en el reto de un momento de confusión, donde los fenómenos cambian a gran velocidad. ¿Quizás una retoma de la crítica como búsqueda de criterio que rige en el fenómeno, mapa del territorio y búsqueda de la orientación en la actualidad?

\section{La necesidad del Estado total: el diagnóstico epocal de Schmitt.}

\subsection{El problema de la técnica.}

Para comprender correctamente la visión schmittiana del problema del Estado total hay que remontarse a un texto de 1929, "La era de las neutralizaciones y las despolitizaciones" , donde elabora una visión amplia, casi de filosofía de la historia more hegeliano, atendiendo a las "etapas que ha recorrido el espíritu europeo". Los últimos siglos de la historia europea la vida espiritual ha tenido cuatro centros de gravedad distintos, esto es, ámbitos de significación a partir del cual todo lo demás adquiere sentido, donde se sitúa las evidencias de las convicciones, los intereses, los éxitos políticos, el asentimiento. Han sido: lo teológico, lo metafísico, lo moral-humanitarista y lo económico-técnico. En el siglo XIX, se trata de lo económico-técnico, que Schmitt analiza con ecos heideggerianos y jüngerianos ${ }^{9}$. Lejos de ser instrumento neutral, la técnica es el nuevo poder que determinará a partir de ahora la estructura y reparto del globo y, con ello, las condiciones bajo las que el hombre habita la tierra.

Estas cuatro etapas suponen correspondientes neutralizaciones: cada ámbito se convierte en un momento dado en lugar de conflicto, por ejemplo, el ámbito teológico en el siglo XVI-XVII. Se neutraliza entonces ese ámbito abandonándolo como centro de gravedad para evitar el conflicto y situando dicho centro en otro ámbito de sentido donde se cree que se encontrará coincidencia, acuerdo y con-

\footnotetext{
Ibidem, p. 47.

Ibidem.

Carl Schmitt, "La era de las neutralizaciones y las despolitizaciones", en C. Schmitt, El concepto de lo político, op. cit., pp. 107-122.

Ibidem., p. 109.

9 Para un análisis más amplio del concepto de técnica en ambos autores, C. Ramas San Miguel, "Técnica, Modernidad y metafísica. Heidegger sobre Jünger”, en Anuario Filosófico 47-3, 2014, pp. 539-566.
} 
senso pacífico universal (la metafísica racionalista-naturalista en el final del siglo XVII). Sin embargo, ese nuevo ámbito neutral pronto se revela como igualmente conflictivo, de modo que siempre es necesario buscar nuevas esferas de neutralidad. Ahora, dice Schmitt, nos encontramos en una situación de fe absoluta en la técnica como suelo puramente neutral: se aboga por despolitizar toda cuestión y ceder su gestión a técnicos expertos, que encontrarán las soluciones más rentables, racionales y asépticas. Ahora bien, la técnica no es nada neutral: "La técnica es siempre instrumento y arma, y porque sirve a cualquiera no es neutral" ${ }^{10}$. Toda política fuerte habrá de servirse de ella, y el sentido definitivo de nuestro siglo "[...] se hará patente se revelará cuando quede claro qué clase política adquiere suficiente fuerza como para apoderarse de la nueva técnica, y cuáles son las verdaderas agrupaciones de amigo y enemigo que prenden sobre este nuevo suelo"11. Por el momento, asevera Schmitt, y frente a la ingenuidad del Estado liberal europeo, que se declara stato neutrale et agnostico frente a la economía y la técnica, parecen ser los rusos los únicos que han entendido que el Estado en cada caso ha de adquirir su fuerza del ámbito central y han hecho realidad la frase cuius regui eius oeconomia, tomándose en serio la cosmovisión tecnicista y dándose a sí mismos una constitución consciente y planificadamente económica.

\subsection{Crisis de Weimar y el "Estado total por debilidad, o cuantitativamente total"}

Schmitt elabora, sobre todo en Legalidad y legitimidad (1932) y El defensor de la Constitución (1931), un diagnóstico de la situación política y jurídica en el final de Weimar. La esterilidad constitutiva del Estado de derecho, empeñado reducir la legitimidad del Estado a un sistema formal de legalidad more positivista, hace fracasar los sistemas legisladores-parlamentarios: falta una voluntad política, soberana, capaz de instituir políticamente un Estado. Los principios de un Estado legislador sucumben al imperio del pluralismo, la policracia y el federalismo. Como señala Kervégan, para Schmitt en los primeros 30 no hay derecho sin política, y lo político ha desbordado lo estatal ${ }^{12}$. Y este fracaso no es un mero vacío, sino que hay aquí un resultado positivo: ha nacido una forma política enteramente nueva, el Estado total. El final de las neutralizaciones no es el final de la política, sino su constitución como totalidad $^{13}$ : aquí es donde se enlaza el análisis de la técnica con el nacimiento del Estado total.

¿Qué es el Estado total para Schmitt? De entrada, un Estado cuyo poder ha sido incrementado extraordinariamente en la era de la técnica, lo cual se manifiesta tanto en su potencia militar como en su aparato de propaganda de masas. Pero ante todo, el resultado de una interpenetración entre la esfera apolítica de la sociedad y la política del Estado, cuya diferenciación era propia de pensamiento liberal del s. XIX; la sociedad civil, presuntamente poblada por individuos que contratan libremente, se revela obedeciendo a la lógica política de la lucha de clases, y el Estado interviene

\footnotetext{
Carl Schmitt, "La era de las neutralizaciones y las despolitizaciones", op. cit., p. 118.

Ibidem, p. 121.

J.-F. Kervégan, op. cit., p. 67.

13 J.-F. Kervégan, Hegel, Carl Schmitt. Lo político: entre especulación y positividad, Madrid Escolar y Mayo, 2007 , p. 106.
} 
en la producción de bienes y la gestión de las poblaciones. El Estado total supone, simultáneamente, la intensificación de su potencia y la extensión de su alcance: en este Estado total, "[...] todo es político, al menos en potencia"14. Pero "Estado total", hay que precisar, mienta para Schmitt dos realidades distintas. En primer lugar hablar Schmitt de Estado total "por debilidad" o "cuantitativamente total", por ejemplo el alemán de $1919^{15}$ : aquél puesto al servicio de intereses económicos, reducido a gestor contingente de las relaciones entre grupos sociales, en detrimento de su universalidad y soberanía indivisible. Es un "Estado social" providencial que no conoce dominio que no pueda ser potencialmente objeto de su injerencia. Es, en las antinomias irresolubles de la lucha de clases, un "régimen de partidos" que pretenden, cada uno, realizar la totalidad en sí mismo y superar el Parlamento. Es, finalmente, un "Estado administrativo" que transforma los medios de acción e instancias de decisión del Estado en formas burocráticas. Se anula así la distinción liberal entre Estado y la sociedad civil, por un doble proceso: primeramente la sociedad civil, vale decir, los intereses organizados y las fuerzas motrices del capitalismo, han sitiado lo político, convirtiéndole en "capitalista colectivo" y organizándose ellos mismos como Estado -"emergencia de la sociedad", "triunfo del animal laborans", diría H. Arendt-16; en un segundo momento, el Estado se apodera de todo lo social, no quedando dominio alguno al margen de una posible intervención política frente al cual el Estado pudiera permanecer neutral -"Biopolítica", diría Foucault; o, como dice Schmitt recuperando la fórmula de Jünger "movilización total"-17. En una palabra: "En el Estado instituido por auto-organización de la Sociedad no existe ya nada que no sea, al menos en potencia, estatal y político"18.

A Schmitt le parecía tan esencial señalar este fenómeno del advenimiento de lo total en la política que publicó estos desarrollos de modo separado en otro texto con el elocuente título "Die Wendung zum totalen Staat" (1931)"19. Hasta el año 33, diagnosticada esta situación de Estado total, Schmitt aún aboga por una salida dentro de este marco constitucionalidad de Weimar: extensión de competencias extraordinarias para una dictadura constitucional plebiscitaria apoyada en la legitimidad democrática -el famoso artículo 48 de la Constitución-. El mérito indiscutible de su diagnóstico es haber acertado a vislumbrar el advenimiento de lo totalitario en política y haberlo nombrado como tal antes del advenimiento del Estado nacional-socialista.

14 C. Schmitt, El concepto de lo politico, op. cit., p. 53 (traducción ligeramente modificada).

15 C. Schmitt y H. Kelsen, La polémica Schmitt/Kelsen sobre la justicia constitucional: El defensor de la Constitución versus ¿Quién debe ser el defensor de la Constitución?, Madrid, Tecnos, 2009, pp. 127-174.

16 "Los movimientos totalitarios pretenden organizar a las masas, no a las clases, [...]. Mientras que todos los grupos políticos dependen de una fuerza proporcionada, los movimientos totalitarios dependen de la pura fuera del número, hasta tal punto que los regímenes totalitarios parecen imposibles, incluso bajo circunstancias por lo demás favorables, en países con poblaciones relativamente pequeñas" (H. Arendt, Los orígenes del totalitarismo, Madrid, Alianza Editorial, 2006, p. 435). Sin embargo, se trata de unas masas especiales: "atomizadas e individualizadas" (ibidem, p. 447).

17 Precisamente Jünger define la técnica como "la movilización del mundo por medio de la figura del trabajador". Su sentido es, pues, "metafísico" (E. Jünger, El trabajador. Dominio y figura, Barcelona, Tusquets, 2003 , p. 146).

18 C. Schmitt y H. Kelsen, op. cit., p. 142 (traducción ligeramente modificada).

19 C. Schmitt, "Die Wendung zum totalen Staat" (1931)", en Positionen und Begriffe im Kampf mit Weimar - Genf - Versailles 1923-1939, Berlín, Duncker \& Humboldt, 1994, pp. 166-178. 


\section{La apuesta: el "Estado total en el sentido de la cualidad y la energía"}

En 1933 Schmitt toma partido y apoya al recién nacido régimen nacional-socialista. Es aquí que Schmitt desarrolla el segundo sentido del concepto "Estado total", "Estado total por la fuerza", con el que quiere mentar esta nueva propuesta política ${ }^{20}$. Habrá que explicar en qué consiste tal propuesta y, con ello, habrá que mostrar que el sentido de este concepto es polémico y lo que pretende ofrecerse con él es una respuesta a la situación del Estado legislador parlamentario, esto es, al Estado total por debilidad.

Schmitt escribe en 1933 otro texto "Weiterentwicklung des totalen Staates in Deutschland“. Allí lo describe con esta contundencia:

Hay un Estado total. Se puede, con gritos de indignación y cólera, rechazar el "Estado total" como bárbaro, esclavista, no alemán o no cristiano: la cosa misma no desaparece por ello de la faz de la tierra. [...]. El Estado total es, en este sentido, al mismo tiempo un Estado especialmente fuerte. Es total en el sentido de la cualidad y de la energía, al modo en que el Estado fascista se llama a sí mismo "stato totalitario", con lo cual se quiere decir, ante todo, que los nuevos medios de poder pertenecen en exclusiva al Estado y sirven al incremento de su poder. Semejante Estado no tolera en su interior ningún tipo de fuerzas enemigas, contenedoras o desintegradoras del Estado. [...]. Semejante Estado sabe distinguir amigo y enemigo. En este sentido, todo Estado auténtico es un Estado total; [...] desde hace tiempo, los teóricos del Estado saben que lo político es lo total, y lo nuevo solo son los nuevos medios, cuyos efectos políticos se deben tener claros ${ }^{21}$.

Aquí se recogen casi literalmente los planteamientos que ya había realizado Schmitt en "La era de las neutralizaciones y las despolitizaciones": no se entienden los textos de estos años sin tener en cuenta aquél de 1929. Los intentos de despolitización y neutralización mediante la técnica sólo han caído en el vacío: "Hay un Estado total" ${ }^{\prime 2}$. De hecho, hay ya una intervención y politización completa de todo ámbito de la existencia humana (cultural, económico, etc.). El proceso de gestión de la vida productiva de las poblaciones y la invasión de lo político por los conflictos de clase, agudizados hasta la excepción y la guerra civil, ya han ocurrido. Han ocurrido porque existe ya, antes de 1933, el "Estado total en sentido puramente cuantitativo": "El Estado pluralista de partidos en Alemania ha desarrollado esta clase de Estado total [...]. Su expansión es causa no de su fortaleza, sino de su debilidad"23. Lo total es, más bien que el Estado como tal, la pluralidad de "partidos totales", que cada uno a su modo quiere intervenir por completo la sociedad.

Los Estados se apropian ya de esa técnica que se ha revelado mortífera y no neutral, pues tienen a su disposición medios técnicos de incalculable poder. La única

20 Una buena reconstrucción del concepto, recogiendo las opiniones de especialistas como Quaritsch, Maschke, Bendersky o Rühters, se halla en J.-F. Kervégan, ¿Qué hacemos con Carl Schmitt? op. cit., pp. 27-44. Una cuestión que escapa al alcance de este estudio es el significado teológico-jurídico o teológico-político de dicha forma de Estado. Cf. J. L. Villacañas, Teología política imperial y comunidad de salvación cristiana. Una genealogía de la división de poderes, Madrid, Trotta, 2016.

21 "Weiterentwicklung des totalen Staates in Deutschland (1933)“, en C. Schmitt, Verfassungsrechtliche Aufsätze aus den Jahren 1924-1954, Berlin Duncker\&Humblot, 1973, pp. 359-365, aquí pp. 360-361.

22 Ibidem, p. 360.

${ }^{23}$ Ibidem, p. 361-362. 
cuestión relevante es si es apropiarse conscientemente de ello o esperar a que lo haga otro. La técnica es siempre sólo instrumento y arma, y porque sirve a cualquiera no es neutral, decía 1929. Ahora replica: "Contra el Estado total solo sirve una revolución igualmente total" 24 . Esta revolución total ofrecerá una respuesta que acabe con el Estado total por debilidad de Weimar y sus neutralizaciones y se apropie del centro de gravedad actual: la técnica. Esta respuesta es lo que llama en este texto Estado "total en el sentido de la cualidad y la energía" 25 .

La vanguardia de esta tendencia se manifestó, según Schmitt, en el Estado fascista italiano. ${ }^{26}$ Es lo que desarrolla en "Wesen und Werden des faschistichen Staates (1929)", donde se trata del siguiente problema específicamente estatal: ¿es pensable que el Estado, frente a las contradicciones e intereses sociales y económicos, juegue hoy el papel de tercero superior, como es la pretensión del Estado fascista? ¿o bien él es necesariamente tan solo el servidor armado de una clase económica y social, según la tesis marxista? ¿o bien es un tercero neutral, como hasta cierto punto es el caso en Alemania? Lo primero que hay que descartar es la tercera opción: como ya se ha dicho, la opción por el Estado neutral supone renegar de lo político mismo. Frente a eso, Rusia e Italia son los únicos que han intentado romper con el cliché del XIX y reflejar los grandes cambios sociales y económicos en la estructura del país también en la organización estatal y en una constitución escrita: sus constituciones son "absolutamente modernas y auténticas «constituciones económicas»" países, la contradicción entre capital y trabajo - la expresión es de Schmitt- es tan aguda, empresarios y trabajadores se hallan enfrentados con un poder tan igualado, que ninguno podría imponer al otro una decisión sin caer en una terrible guerra civil, luego las decisiones esenciales no pueden tomarse por el camino legal: lo único que puede hacer el Estado es permanecer neutral, sin decidir. "Una preeminencia del Estado frente a la economía sólo puede llevarse a cabo con ayuda de una organización cerrada y conforme a un orden": Italia y Rusia requiere de un tal "aparato" si quiere mantener esa supremacía. La apuesta de Schmitt, que retomará en 1933, es que el Estado pueda ser "tercero superior":

¿Cómo podría el Estado ser el tercero superior y poderoso, si no tuviera a su disposición una organización fuerte, bien asentada, jerárquica, cerrada sobre sí misma y por lo tanto no, como los partidos, sustentada en la libre competencia? [...] El Estado fascista decide no como tercero neutral, sino como tercero superior. Esta es su supremacía ${ }^{28}$.

El Estado nacional-socialista de 1933 proseguiría esta tendencia. Se caracteriza por apropiarse de conscientemente de esos nuevos medios técnicos, que sirven al incremento de su poder. ¿Cuáles son estos nuevos medios para el Estado, mediante los cuales alcanza esas "posiciones de poder que han de ser conquistadas y afirmadas

$24 \quad$ Ibidem, p. 360.

25 Ibidem, p. 361.

26 C. Schmitt, "Wesen und Werden des faschistischen Staates (1929)", en Positionen und Begriffe im Kampf mit Weimar-Genf-Versailles 1923-1939, op. cit., 124-130, aquí p. 127. Sobre Schmitt y el Estado fascista italiano, R. Bueno, "A cultura política do fascismo: Benito Mussolini e Carl Schmitt", en Boletín mexicano de derecho comparado 9 (Mayo-Junio), 2017, pp. 613-644.

27 C. Schmitt, "Wesen und Werden des faschistischen Staates (1929)", op. cit., p. 127.

$28 \quad$ Ibidem, p. 128. 
cada día"29" Schmitt responde en "Machtpositionen des modernen Staates", de 1933, un texto muy peculiar dedicado a construir el "consenso" o hegemonía que constituye el "verdadero poder" político ${ }^{30}$.

\section{1. La apropiación de los medios técnicos}

Lo primero que define al Estado total por la fuerza es, primero, la apropiación del centro de gravedad técnico, que incluye manifestaciones de lo técnico, lo económico y lo bélico, todos los cuales se fusionan en una gran corriente.

\subsubsection{Medios de comunicación de masas}

Los medios que debe poseer el Estado son los métodos según los cuales se construyen la opinión pública y la voluntad del pueblo, lo que se ha llamado "el plebiscito de todos los días". Así, lo determinante para Schmitt no sería el monopolio de la violencia armada y militar, ni el monopolio de los nuevos técnicos de tráfico y transporte, a pesar de que uno y otro garantizan poder político armado y centralizado, sino los medios de comunicación de masas que construyen consenso. En la época liberal, la prensa era la herramienta técnica adecuada para construir opinión pública, y era una reivindicación política el exigir su libre ejercicio, en consonancia con una concepción de lo político fundada en los derechos individuales. Hoy, en la era de la técnica y la democracia de masas, dice Schmitt, son la radio y la televisión los medios en donde se juega la formación de una voluntad y opinión: estos medios superan de lejos a la prensa impresa en su capacidad de producir efectos a nivel de psicología de masas, debido a su rapidez y ámbito ilimitado de propagación de información, así como al impacto subjetivo de lo visual. Por tanto, el control de tales medios es una cuestión política de primer orden, y ningún Estado, pese a las proclamaciones de libertades y derechos fundamentales, puede dejar de tomarlas a su mando. Éste se hallaría ante la siguiente disyuntiva: "Ha de renunciar o bien al concepto heredado liberal de libertad, o bien a una parte decisiva de su poder, esto es, a su existencia política" ${ }^{31}$. Como lo segundo es imposible, lo primero se traduce en una simple opción: monopolio o censura.

Este tipo de análisis de los nuevos medios técnicos de masas resulta cercano al que realizó W. Benjamin en La obra de arte en la época de su reproductibilidad técnica, donde acaba respondiendo a qué consecuencias políticas tienen los avances técnicos que afectan al arte, especialmente aquellos que permiten la reproductibilidad ilimitada. Benjamin y Schmitt responden que los avances técnicos como la radio o la televisión permiten ante todo acercar todas las cosas en el espacio-tiempo. Con ello se las torna disponibles en forma de imagen, se pone una "presencia masiva en lugar de una presencia irrepetible", y todo lo dado puede ser reproducido. Este flujo vertiginoso de imágenes no invita a la contemplación sino que genera una "acción de shock" 32 . La "recepción visual", frente a la táctil, tiene una lógica específica. Sobre

29 C. Schmitt, "Machtpositionen des modernen Staates (1933)", en Verfassungsrechtliche Aufsätze aus den Jahren 1924-1954, op. cit., pp. 367-371, aquí p. 368.

30 Ibidem.

31 Ibidem, pp. 368-369.

32 W. Benjamin, La obra de arte en la época de su reproductibilidad técnica [Urtext], México D.F., Editorial Ítaca, 2003 , p. 95. 
ello, Benjamin recoge una cita de Duhamel: "Ya no puedo pensar lo que quiero pensar, las imágenes móviles se han puesto en el lugar de mis pensamientos"33; quizás, los versos de Goethe que cita Schmitt sobre cómo la imagen hipnotiza y esclaviza al espíritu son un eco de esa referencia.

Ambos subrayan una inclusión de las masas a todos los niveles, también de sujeto político. La obra, dice Benjamin, a diferencia de lo que ocurría anteriormente, reúne a la masa en un espacio de recepción simultáneo y colectivo: en lugar de sumergirse uno en el recogimiento, en la obra, "la masa [...] hace que la obra de arte se hunda en ella, la baña con su oleaje, la envuelve en su marea. sumerge en sí misma a la obra de arte" ${ }^{34}$, recibiéndola en la dispersión y dispuesta a ser movilizada por ella. También en la elaboración de los productos culturales participa la masa como especialista que expresa su opinión (concursos en televisión, votaciones desde casa). Las masas también participan, en fin, como objeto: "A la reproducción masiva corresponde en efecto la reproducción de masas [...] la masa se mira a la cara en los grandes desfiles festivos, en las asambleas monstruos, en las enormes celebraciones deportivas y en la guerra, fenómenos todos que pasan ante la cámara. [...]. Los movimientos de masas se exponen más claramente ante los aparatos que ante el ojo humano" ${ }^{35}$. En suma: los movimientos de masas y la guerra representan una forma de comportamiento humano especialmente adecuada a los aparatos técnicos ${ }^{36}$.

Por último, Schmitt proponía que el Estado tomara a su cargo estos medios técnicos, porque es el ámbito donde se juega hoy el conflicto y la posibilidad de agrupaciones decisivas. Está en plena consonancia con la observación de Benjamin del Estado fascista como aquel cuya política se cifra en el uso de recursos técnico-estéticos.

\subsubsection{Medios económicos}

En cuanto a los medios económicos, era necesario para Schmitt dirigirlo conscientemente, mediante un gran poder político. De hecho, ya se interviene ampliamente la economía, también en el liberalismo. Un Estado que no lo hiciera tendría que declararse neutral respecto de las cuestiones y decisiones políticas, pues lo político, el conflicto, se juega hoy en ese terreno ${ }^{37}$. Italia y Rusia, en los años 20 , lo han comprendido. La contradicción entre capital y trabajo es tan aguda que ninguno podría imponer al otro una decisión sin caer en una terrible guerra civil, luego las decisiones esenciales no podían tomarse mediante la mediación legal, sino sólo con "una organización cerrada y conforme a un orden" o aparato jerárquico y autoritario. Este

\footnotetext{
Ibidem, p. 91.

Ibidem, p. 93.

Ibidem, nota 17, p. 112 (traducción ligeramente modificada).

No hay más que pensar en los documentales de L. Riefenstahl De ahí la fórmula de Benjamin para caracterizar lo específico del fascismo: "esteticismo de la política", o, como reformulaba Lacoue-Labarthe, un "nacionalesteticismo". Esta convergencia entre estética y política totalitaria también la hizo notar Robert Musil (cf. J. C. Cruz Revueltas, La incertidumbre de la Modernidad. Roberto Musil o la interpenetración de la razón y el sentimiento, México, Publicaciones Cruz, 2002, p. 111 ss.). Goebbels afirmó que la política es un arte "[...] tal vez el más elevado y el más extenso que exista, y nosotros, que damos forma a la política alemana moderna, nos sentimos como artistas que forman imagen sólida de un pueblo a partir de una masa bruta. Igual que el artista, al dar forma elimina lo malsano, el político cuida por que sólo se dé el arte de calidad"(Goebbels citado por P. Lacou Labarthe, La fiction du politique, Strasbourg, Association de Publications près des Universités de Strasbourg, 1987, p. 53).

37 C. Schmitt, El concepto de lo político, op. cit., p. 115.
} 
protagonismo de la economía planificada en ningún caso mina para Schmitt el poder político como tal; es, al revés, es su más rigurosa expresión: “[...] no es que los que planifican dominen y gobiernen, sino al contrario: los que dominan y gobiernan, planifican"38. Para Schmitt, sólo un Estado fuerte pacificará el desgarramiento de las antinomias socio-económicas que asedian lo político. Una cuestión que se plantea aquí es si esta transformación es una radicalización del Estado (Adorno, Horkheimer) o su liquidación (Foucault, Neumann): luego entraremos en ella.

\subsubsection{Medios bélicos: la guerra total}

En un par de escritos sobre la guerra, que considera "un intento de continuación de mi El concepto de lo político"39, Schmitt investiga la vinculación de la cuestión de Estado total con la guerra total. Y es que "En la guerra se esconde el corazón de las cosas. A partir del tipo de guerra total se determinan el tipo y forma de la totalidad del Estado; a partir del tipo especial de las armas decisivas se determinan el tipo y forma de la totalidad de la guerra. Pero la guerra total recibe su sentido del enemigo total" 40 . Así, el Estado total encuentra su inteligibilidad en la guerra total, determinada a su vez por los medios técnicos de armamento; pero ésta sólo recibe su sentido de las configuraciones de amigo-enemigo, esto es, lo político. Es el esquema de El concepto de lo político: la esencial vinculación entre Estado y guerra en el pensamiento de Schmitt se manifestará con peculiar claridad en el caso del Estado total por fuerza. Pues a la existencia del Estado total como trastrocamiento de la forma clásica de Estado lleva consigo asimismo modificaciones en el ser de la guerra, especialmente visibles desde la Primera Guerra Mundial. Schmitt las caracteriza siguiendo a Jünger y su concepto de "movilización total"41. Ésta no hace al soldado el tipo dominante, sino que asume y supera [aufhebt] la distinción entre soldado y civil. Las dos caras se transforman: la guerra se convierte en "[...] herramienta de grupos dominantes de poder económico" ${ }^{2}$. Movilización total, entonces, mienta un concepto simultáneamente bélico y económico: se trata de movilizar la corriente de vida de una población, que se convierte en grados de intensidad, de energía un gran proceso de trabajo, de auto-reproducción de una vida que se mina, como toda vida biológica, a si misma desde dentro, y del cual la producción y la destrucción no son sino momentos sucesivos. Esta fusión entre lo bélico y lo económico supone que no es posible determinar ya con claridad si se está en la guerra o en la paz, en parte a causa de tratados de paz confusos y oportunistas, pero sobre todo por "la extensión de la representación de la guerra a ejercicios de enemistad no militares (económicos, propagandísticos, vidas civiles). Se hace de la paz una ficción jurídica al declarar como paz lo que no es "la guerra militar al viejo estilo con animus belligerandi". ¡Menuda paz! "Para los actores de la coacción económica, evitar la guerra militar del viejo estilo es un juego de niños" ${ }^{\text {"43 }}$. Cuando sectores no militares se incluyen en los

\footnotetext{
38 C. Schmitt, "Machtpositionen des modernen Staates (1933)“, op. cit., p. 371.

39 C. Schmitt, "Totaler Feind, totaler Krieg, totaler Staat (1937)", en Positionen und Begriffe, op. cit., pp. 268-285;

C. Schmitt, "Über das Verhältnis der Begriffe Krieg und Feind (1938)”, en ibidem, pp. 278-285, aquí p. 279.

40 C. Schmitt, "Totaler Feind, totaler Krieg, totaler Staat (1937)", op. cit., p. 270.

41 E. Jünger, Sobre el dolor. Seguido de La movilización total y Fuego y movimiento, Barcelona, Tusquets, 1995.

42 C. Schmitt, "Totaler Feind, totaler Krieg, totaler Staat (1937)", op. cit, p. 271.

43 C. Schmitt, "Über das Verhältnis der Begriffe krieg und Feind (1938)", op. cit, p. 284.
} 
enfrentamientos hostiles y definen al enemigo, es un cambio no solamente cuantitativo, sino cualitativo: una intensificación de la hostilidad, que ahora es total, abarca todos los ámbitos de la existencia.

Por estos tres motivos, el Estado total es especialmente fuerte: hace uso de todos los medios a su alcance para aumentar su poder, de los cuales los técnicos son los más preminentes de la época. Esto, señala Schmitt, permite replantear un viejo problema político: la relación entre poder estatal y consenso o asentimiento del pueblo. Schmitt critica a los que oponen poder del Estado y asentimiento, reconocimiento, aclamación o confianza del pueblo, en una palabra, consenso: "Un verdadero consenso produce un verdadero poder y viceversa" ${ }^{44}$. Pues un poder estable encuentra siempre un asentimiento seguro del pueblo, no puedo construirlo con medios meramente mecánicos. A este comienzo de tintes gramscianos ${ }^{45} \mathrm{Schmitt}$ le imprime un giro: una dictadura o un Estado totalitario, afirma repetidas veces, son anti-liberales, pero no necesariamente anti-democráticos: pueden recoger, por acclamatio de un líder, la voluntad de un pueblo.

En suma, la defensa schmittiana de un Estado fuerte trata de ser una respuesta mediante la fuerza a las antinomias socio-económicas que asedian lo político, es decir, un intento de eliminar el Estado total por debilidad.

\subsection{La estructura: Estado, Movimiento, Pueblo}

En cuanto a la arquitectura institucional de este nuevo Estado, se caracteriza por un rechazo frontal de los métodos y estructuras políticas liberales. La nueva organización, en una triple articulación, se propone en "Estado, Movimiento, Pueblo" $(1933)^{46}$ : el "Movimiento" o Partido como nuevo lugar de lo político desborda lo estatal. En primer lugar se constata el derrocamiento del Estado: "El Estado, como administración y burocracia pierde el monopolio de lo político, que había conseguido en los s. XVII y XVIII. Hoy en día lo político ya no puede determinarse desde el Estado, sino que el Estado debe determinarse a partir de lo político"47.

Aquí se ve claramente lo que se apuntaba en esa observación de Schmitt sobre el totalitarismo, a saber, que no hay que entender a éste como la consumación de una suerte de tendencia interna omniabarcante del Estado, bien al contrario, su centro político dinamizador es un Partido que asedia desde fuera al Estado. En esto, por cierto, está Schmitt de acuerdo con Foucault y Neumann, y no con la visión de la Escuela de Frankfurt. Como señala Foucault, toda una serie de argumentos que parten de un núcleo común de fobia al Estado afirman que el Estado posee en sí mismo y en virtud de su propio dinamismo una especie de poder de expansión, una tendencia intrínseca a crecer, un imperialismo endógeno que lo empuja a invadir lo que es para él su otro, su blanco, su objeto la sociedad civil. Así, el totalitarismo no sería más que la consumación de la tendencia interna connatural al Estado: habría un parentesco o continuidad

44 C. Schmitt, "Machtpositionen des modernen Staates (1933)", op. cit., p. 370.

45 Sobre las conexiones entre Gramsci y Schmitt, A. Kalyvas, "Soberanía hegemónica: Carl Schmitt, Antonio Gramsci y el príncipe constituyente", en Las torres de Lucca. Revista internacional de filosofía política, 11, 2017, pp. 193-248.

46 C. Schmitt, Staat. Bewegung, Volk. Die Dreigliederung der politischen Einheit, Hamburg, Hanseatische Verlagsanstalt, 1933. Sobre la estructura institucional del Estado nazi, R. Bonnard, Le Droit et l'Etat dans la doctrine nationale-socialiste, Bordeaux, Librairie générale de Droit et de Jurisprudence, 1939.

47 C. Schmitt, Staat. Bewegung, Volk, op. cit., p. 15. 
entre las distintas formas estatales (benefactor, burocrático, fascista, totalitario). Esta tesis ha sido sostenida por parte de algunos marxistas, pero encuentra su nacimiento, curiosamente, en los liberales, que esgrimían estos argumentos ya desde los años 30 . Foucault afirma contra eso: "Ese llamado Estado totalitario no es en absoluto la exaltación del Estado, constituye, por el contrario, una limitación, una disminución, una subordinación de su autonomía, su especificidad y su funcionamiento característico con respecto a algo distinto, ¿el qué? el partido"48. El Estado totalitario no es el Estado administrativo del XVIII, el Polizeistaat del XIX llevado al extremo: su principio no es la gubernamentalidad de Estado, sino la de partido. "No debemos engañarnos sobre la pertenencia del Estado a un proceso de fascistización que le es exógeno y que compete mucho más a su decrecimiento y dislocación"49. Lo que hay hoy, dice Foucault, no es el crecimiento del Estado, sino su decrecimiento, en dos formas: por gubernamentalidad totalitaria de partido y por gubernamentalidad liberal.

Encontramos un diagnóstico similar el Neumann ${ }^{50}$. Al contrario que Pollock, Adorno o Horkheimer, que comprenden el régimen nacional-socialista como "capitalismo de Estado" o una radicalización del dominio estatal sobre el campo económico, esto es, como despliegue de la racionalidad estatal moderna, Neumann habla en términos de "economía monopolista totalitaria", que viene a anular los principios de dicha racionalidad. En efecto, se elimina la independencia del poder judicial, se devalúa el poder legislativo del Reichstag, se disuelve incluso el monopolio estatal sobre el poder coactivo con la aparición de poderes para-militares y para-estatales, se eliminan los límites a la acción penal. En suma, se da una funcionalización absoluta del aparato público con respecto a las exigencias del capitalismo monopolista, que afronta la erradicación de resistencias a ello, cuando la democracia política, dominada por una fuerte social-democracia y sindicatos, no podía satisfacer ya esas exigencias. De este modo se resignifica el Estado: hacia el interior, con la creciente referencia al "movimiento" que ha de guiar el aparato estatal; hacia el exterior, desbordando el derecho internacional por la referencia a los imperios enfrentados y el derecho de los Volksgruppen, más allá de la soberanía estatal. En conclusión, lejos de intensificarse, se anula la racionalidad estatal moderna.

Volviendo a Schmitt, con la preeminencia del Estado cae también la concepción tradicional positivista del derecho como norma, y ésta como producto de instituciones administrativas-estatales, en suma, el derecho como "conjunto de las reglas de la acción estatal", como "modo funcional de las instancias y autoridades existentes": se revela su carácter mecánico e instrumental y deja paso al Derecho "en sentido substancial", al que corresponde el aseguramiento de la unidad político mediante las decisiones incuestionadas, y por ello políticas; esto es, según se nos explica en el infame "Der Führer schützt das Recht", cuando el Führer como juez supremo crea derecho inmediatamente ${ }^{51}$. Se muestra aquí el decisionismo schmittiano en materia de derecho. La autoridad prueba que, para emplear el derecho, no tiene necesidad de derecho, decía en Teología Política. Este esquema decisionista quedará sustituido en 1934 por el del "orden concreto", que primará desde entonces.

\footnotetext{
48 M. Foucault, El nacimiento de la biopolítica. Curso del Collège de France (1978-1979), Tres Cantos, Madrid, 2009 , p. 193.

49 Ibidem.

50 F. Neumann, Behemoth. Pensamiento y acción en el nacional-socialismo, 1933-1944, Madrid, Anthropos, 2014.

51 C. Schmitt, "Der Führer schützt das Recht (1934), en Positionen und Begriffe, op. cit., p. 227-232.
} 
La nueva estructura de lo político, no centrada ya entonces en el aparato de Estado ni en el derecho como corpus de normas, se fija a partir de la "Constitución provisional" que es la Ermächtigungsgesetz de marzo del $33^{52}$. Posee una triple estructura ${ }^{53}$ :

- Estado: En sentido restringido, la parte político-estática: el funcionariado estatal y el Éjército, la organización de gobierno, Administración y Justicia. En sentido amplio, el todo de la unidad política de un pueblo.

- Movimiento: Elemento político-dinámico. Partido como cuerpo político reclutado de todas las capas del pueblo pero dirigido jerárquicamente.

- Pueblo: Cara no política bajo protección de las decisiones políticas: la auto-administración comunitaria y un orden socio-económico que reposa en proximidad local y que no es estatal, pero sí público-jurídico.

El Führer político ha de apoyarse en el Partido, que, como organización del movimiento, porta en sí tanto el aparato de Estado como el orden socio-económico del pueblo; ambas instancias le reconocen como autoridad última: "La fortaleza del Estado nacional-socialista radica en que está dominado y atravesado, de arriba abajo y hasta su último átomo, por el pensamiento del caudillaje [Führertum]"54. Este principio del Führer se complementa con la "igualdad de estirpe" - Artgleichheit: en el contexto, se entiende pureza racial-, que garantiza la identidad entre dirigente y $\operatorname{dirigidos}^{55}$.

\subsection{La finalidad: Unidad y distinción amigo-enemigo}

Si Schmitt admira el Estado totalitario de 1933 es porque le parece la manifestación transparente, derrotadas las neutralizaciones tradicionales, de la esencia de lo político: unidad, y distinción amigo-enemigo. Pese a que es del todo manifiesta, como por lo demás él mismo reconoce, la destrucción de la estructura clásica del Estado europeo, Schmitt defiende que se consuma y mantiene la esencia de lo estatal.

Por un lado, la búsqueda de unidad por encima del pluralismo de fuerzas en pugna que descomponen lo social como se había diagnosticado en el Estado total por debilidad: "[...] en la Alemania nacional-socialista de Estado único se ha superado el peligro de un tal desgarramiento pluralista de Alemania en varios partidos en sí totales[...]. Semejante Estado no tolera en su interior ningún tipo de fuerzas enemigas, contenedoras o desintegradoras del Estado. [...]. Semejante Estado sabe distinguir amigo y enemi-

52 C. Schmitt, Staat, Bewegung, Volk, op. cit., p. 6 ss. Los nuevos cargos jurídicos son: Presidente (se conservan sus derechos como cabeza de autoridad el Estado, aunque no gobierna), Canciller ("el Führer político del pueblo alemán”), Gobierno (NSDAP), Reichstag y Reichsrat. Las nuevas formas de legislación: decisión del Gobierno, consulta al pueblo mediante votación, y permanecen abiertas las de Weimar (decisión del Reichstag y referéndum). En cuanto a la jerarquía, el Führer político posee preeminencia incondicionada, incluso contra la voluntad del Reichstag, y para dirimir posibles conflictos entre la opinión del pueblo y la del gobierno. Se viene abajo la división de poderes y el gobierno posee un auténtico derecho de legislar. Se suprimen las elecciones al modo burgués entre partidos plurales e incompatibles, en sí totales, en favor de un Estado de partido único.

53 Ibidem, p. 12 ss.

$54 \quad$ Ibidem, p. 33.

55 Agamben, comentando esta parte, señala la tesis foucaultiana acerca del racismo totalitario como el modo en que el nuevo biopoder que se presentaba como gestión de la vida se reconciliaba con el poder soberano sobre la vida y la muerte. Aquí en Schmitt, dice Agamben, es clarísimo: la distinción amigo-enemigo, que pasa a designar lo racialmente afín o desemejante, se introduce en el "cuerpo despolitizado", como un umbral en el que lo político pasa continuamente hacia lo impolítico como gestión del cuerpo biológico (G. Agamben, op. cit., p. 466). 
go" ${ }^{25}$. En la tercera parte de Staat, Bewegung, Volk, se analiza el devenir histórico de la estructura dual del Estado liberal burgués - poder estatal y Libertad individual-, cuando poderosas organizaciones copan el espacio no estatal -pero sí político- de lo social: "Tras el velo de la libertad democrático-liberal y del Estado de derecho burgués puedo emerger así el sistema pluralista de un Estado de partidos, como ha sido característico en los 14 años de Constitución de Weimar"'57. Frente a ese conflicto, unidad de partido único, Führer como instancia suprema, no división de poderes: sólo así, afirma Schmitt, se salva al Estado de convertirse, al modo liberal-democrático, en una herramienta ciega de poderes no estatales-sociales, esto es, políticamente irresponsables e invisibles.

Lo segundo se anunciaba en otros textos: "Semejante Estado no tolera en su interior ningún tipo de fuerzas enemigas, contenedoras o desintegradoras del Estado. [...]. Semejante Estado sabe distinguir amigo y enemigo" 58 . Aquí se precisa:

La Constitucíón de Weimar ya no es válida [...]. Tampoco para la aniquilación del enemigo del pueblo y de Estado, el Partido Comunista, podía uno esperar hasta la autorización de un sistema que por su propia debilidad y neutralidad ni siquiera era capaz de distinguir un enemigo mortal del pueblo alemán [...]. Ésta [la Constitución de Weimar] deja de ser idéntica consigo misma una vez cae el mundo de pensamiento liberaldemocrático en su conjunto, cuando por ejemplo deja de haber fundación indistinta de partidos; cuando deja de haber libertad política de competencia, de opinión, de espíritu y de acción, incluyendo los esfuerzos contrarios al Estado; cuando deja de haber, en fin, una neutralidad e igualdad como imagen del mundo que lleva hasta el suicidio, esto es, no distinción entre amigo y enemigo del Estado, entre semejantes y extraños al pueblo ${ }^{59}$.

Este enemigo tiene en ese momento un nombre muy claro: el Partido Comunista. "Sólo con el nombramiento como canciller de Adolf Hitler por el Presidente el 30 de enero de 1933 recuperó de nuevo el Reich alemán una dirección [Führung] política y el Estado alemán encontró la fuerza para aniquilar al marxismo enemigo del Estado"60. Así, Schmitt acusa al Gobierno de Weimar de no haber sido capaz de reconocer al enemigo del pueblo alemán, el Partido Comunista, en un gesto de debilidad y neutralidad propio de todo Estado liberal, basado en la indecisión y las libertades sin criterio. Las formulaciones pueden resultar chocantes si se recuerda el tono halagador a los trabajadores en el texto del 29 sobre el Estado fascista italiano, donde a la pregunta de si dio Estado, "según su esencia y a largo plazo", serviría a los intereses capitalistas de los empresarios o a los socialistas de los trabajadores, respondía: "Supongo que él, y en la misma medida en que es un verdadero Estado, a largo plazo beneficiará a los trabajadores, y ello porque éstos son hoy el pueblo y el Estado no es sino la unidad política del pueblo. Sólo un Estado débil es el sirviente capitalista de la propiedad privada" ${ }^{\circ}$. Añade que los capitalistas tienen que temer un Estado fascista, que devendrá

\footnotetext{
C. Schmitt, Staat, Bewegung, Volk, op. cit., p. 11.

Ibidem, p. 25.

C. Schmitt, "Weiterentiwcklung des totalen Staats in Deutschland (1933)", op. cit., p. 361.

C. Schmitt, Staat, Bewegung, Volk, op. cit., pp. 5-6.

60 Ibidem, p. 31. Decimos "en ese momento" porque el marxismo no se juzga ideológicamente como enemigo per se, sino por incapaz de generar un orden concreto de amigo-enemigo. Todo derivado de la a-politicidad liberal jugaría para Schmitt este papel de enemigo.

61 C. Schmitt, "Wesen und Werden des faschistischen Staates (1929)", op. cit., p. 129.
} 
"Estado de trabajadores" con una economía planificada, y ello sin dejar de ser "tercero superior", pues la fortaleza de un Estado, sostiene, no se muestra en ser idénticos a los económicamente fuertes, sino en ejercer su poder contra ellos.

\section{Conclusiones}

Schmitt, en síntesis, ha caracterizado el "Estado total por la fuerza" del modo siguiente.

- Un Estado que busca el incremento de su poder apropiándose del centro de gravedad técnico, esto es, de todos los medios a su alcance: de masas, económicos y bélicos.

- Una nueva triple estructura política de Estado, Movimiento y Pueblo que desbanque la estructura dual sociedad civil -Estado propia del Estado liberaladministrativo decimonónico.

- Un Estado que logra intensificar su esencia, esto es, unidad y distinción eficaz de los enemigos del Estado.

Desde todo ello se busca es ofrecer una respuesta a la situación de "Estado total por debilidad", o disolución y desbordamiento de lo político por lo social en la crisis constitucional alemana: un Estado capaz de decidir, como instancia soberana, por encima de los conflictos que desgarran la unidad política ${ }^{62}$. En esa medida, este segundo uso del concepto "Estado total" designa el intento de pensar una solución a la crisis del Estado total por debilidad.

Indudablemente marcadas por el oportunismo político, a la luz de los desarrollos generales de la cuestión del Estado total por fuerza pueden distinguirse distintas posiciones en las tesis de Schmitt. En el texto de 1929 se presenta a los trabajadores como una fuerza social potencialmente universal, es decir, la que puede constituirse como representante del bien común y un nuevo contrato social, y a las élites capitalistas como una minoría sobre la que debe imponerse el Estado. Siguiendo la estrategia del primer fascismo italiano, se reconoce el papel de los trabajadores como sujeto político y se pretende defender un Estado superior a los intereses de clase en general, el "tercero superior". Por el contrario, en 1933 se considera al Partido Comunista portavoz y representante de uno de los dos lados de ese equilibrio mortal entre trabajo y capital que mantiene desgarrado al Estado, y por tanto su enemigo. Aquí el nuevo sujeto general sería un "pueblo" organizado orgánicamente y movilizado por el Partido único.

62 En el por otra parte aberrante por sus infames comentarios antisemitas El Leviatán en la doctrina del Estado de Thomas Hobbes, se encuentra sin embargo algo sugerente respecto de las limitaciones de este modelo de Estado fuerte. En el apartado "La persona soberano-representativa muere a causa de la separación entre lo interno y lo externo", en unas líneas sorprendentemente premonitorias, que de hecho retoma en sus escritos del 45-47 desde la prisión en Berlín, Schmitt describe cómo cuando el poder público es solamente público, "el alma del pueblo se entrega al 'camino misterioso' que conduce hacia el interior" -la referencia es a la famosa frase de Novalis(C. Schmitt, El Leviatán en la doctrina del Estado de Thomas Hobbes, México D.F., Fontamara, 2008, p. 134). La situación es la descrita, afirma Schmitt, por E. Jünger en Sobre los acantilados de mármol, "un libro que describe con gran audacia los abismos que se esconden tras las máscaras de orden del nihilismo" (C. Schmitt, Ex captivitate Salus. Experiencias de la época 1945-1947, Madrid, Trotta, 2010, p. 34). A la postre, y como llegó a reconocer también Heidegger, el estado nazi se desvela como la última máscara, en forma de orden y de dominio técnico planetario, del nihilismo. Ése era el abismo: un Estado totalitario que, como puro dominio técnico y mediante el terror, no podría más que expulsar, aplastar y reprimir a su propia población. 
En ambos casos, es una postura teórica irrenunciable de Schmitt el considerar que "el enemigo" será todo aquél que impida la existencia de un Estado como unidad fuerte, y es un deber de dicho Estado identificar qué fuerzas portan ese peligro en cada momento, localizarlas y destruirlas. Lo constante es, pues, la defensa del Estado frente a las fuerzas "enemigas" que lo disgregan o debilitan. Más allá del evidente oportunismo, es cierto que tal postura es coherente con las posiciones mantenidas por Schmitt en su teoría del Estado. En 1930 escribía "Ética del Estado y Estado pluralista", como crítica de la situación de pluralidad y debilidad y reclamación de la vuelta de un Estado fuerte que garantizara la unidad. Aquí se vislumbra ya lo provisorio del concepto de "Estado" en su sentido clásico:

Naturalmente que es posible limitar históricamente la palabra "Estado" al Estado absoluto de los siglos XVII y XVIII. Entonces es fácil combatirla hoy éticamente. Pero no se trata de la palabra, que tiene su historia y que puede dejar de ser moderna, sino de la cosa, a saber, el problema de la unidad política de un pueblo. Aquí rige ahora, como en casi todas partes, también en los teóricos sociales pluralistas, el error, que permanece en una inconsciencia acrítica, de que lo político significa una sustancia propia junto a otras sustancias de "asociaciones sociales", de que junto a la religión, la lengua, la cultura y el derecho presenta un contenido específico, [...]. Pero justo aquí yace el malentendido. En verdad lo político sólo designa el grado de intensidad de una unidad. La unidad política puede por tanto tener y abrazar en sí diferentes contenidos. Pero ella designa siempre el grado más intensivo de una unidad, a partir de la cual también se determina la distinción más intensiva, a saber, la agrupación de amigos y enemigos [...] La unidad política es la unidad suprema, y no porque dictamine todopoderosamente o porque nivele a las demas unidades, sino porque es la que decide y porque puede evitar que dentro de ella todas los demás agrupaciones sociales se disocien hasta la enemistad extrema (esto es, hasta la guerra civil) ${ }^{63}$.

Si algo demuestra el posterior desarrollo de la noción de "Estado total" es que Schmitt estuvo dispuesto de buen grado a renunciar a la tan querida por él arquitectura del Estado clásico del Ius Publicum Europaeum con tal de mantener su concepto de lo político: unidad y distinción amigo-enemigo. Para Schmitt, entonces, lo político determina el Estado: no viceversa. También en esto anticipa no pocos desarrollos, a derecha e izquierda, de la filosofía contemporánea ${ }^{64}$.

63 C. Schmitt, "Ética de Estado y Estado pluralista", en Logos. Anales del Seminario de Metafisica (trad. de Clara Ramas San Miguel) 44, 2011, pp. 21-34, aquí p. 29.

64 Agamben va tan lejos como para afirmar incluso que Staat, Bewegung, Volk "describe los principios constitutivos de las sociedades post-democráticas del siglo XX en cuya estela nos movemos todavía hoy. [...] contiene lo que podemos llamar el arcanum de la teoría de Schmitt del derecho público [...]”. Agamben, op. cit., p. 464. Desde sus contemporáneos Lukács, Marcuse, Löwith, Benjamin, Kojève, Jünger, el impacto de Schmitt en pensadores de todas las tendencias no ha parado de crecer. Desde la izquierda italiana de los 70 (Marramao, Negri, Tronti, Agamben); hasta los juristas de la República Italiana (Mortati, Bobbio); pasando por los estudiantes de izquierda alemanes (Rudi Dutschke y el SDS, que habían escuchado a Kojève decir en 1967 que lo único interesante que podía hacerse en Alemania era volver a Schmitt); la polémica alemana de 86, cuando E. Kennedy afirmó que la Escuela de Frankfurt se había alimentado de él; acabando con Derrida, Habermas o Mouffe. Concluye Kervégan: un hilo de Ariadna conduce desde el pensamiento de Schmitt al de Habermas (y Mouffe), y, a través de él, al pensamiento liberal, democrático (y populista) (J.-F. Kervégan, ¿Qué hacemos con Carl Schmitt? op. cit., pp. 45-62). 